\title{
Introduction from the Editors
}

\author{
Harold Kim $^{1,2^{*}}$, Richard Warrington ${ }^{3}$ and Wade Watson ${ }^{4}$
}

In 2011, we published a comprehensive supplement entitled, A Practical Guide for Allergy and Immunology in Canada, in this journal. The main objective of this supplement was to provide medical students, medical residents, primary-care practitioners and other healthcare professionals with a comprehensive, yet easyto-follow, series of peer-reviewed articles focussed on all of the common conditions we deal with in the field of allergy and immunology. We believe this objective was achieved since the articles have been downloaded and accessed hundreds of thousands of times. Also, hard copies of the supplement were distributed to thousands of Canadian medical students and residents. Given the high level of readership and interest in these articles over the last 7 years, we felt that it was important to publish updates on the topics addressed in the supplement. In addition, given recent advances in the field of food allergy, we have added an article on early food introduction and have divided the topic of food allergy into two separate papers.

The first article in the supplement provides a basic introduction to the main components and function of the immune system and its role in both health and disease, and serves as a background to the immunopathological disorders discussed in the remainder of this supplement, including asthma, allergic rhinitis, atopic dermatitis (AD), anaphylaxis, food allergy/hypersensitivity, eosinophilic esophagitis (EoE), urticaria, angioedema, drug allergy and primary immunodeficiency disorders (PIDs). Asthma remains the most common chronic respiratory disease in Canada [1], and despite significant improvement in the diagnosis and management of this disorder, the majority of Canadians with asthma remain poorly controlled [2]. In most patients, however, control can be achieved

*Correspondence: hlkimkw@gmail.com

${ }^{1}$ McMaster University, Hamilton, ON, Canada

Full list of author information is available at the end of the article through the use of avoidance measures and appropriate pharmacological interventions. In recent years, three novel biologics have been approved in Canada for the treatment of severe asthma. Allergic rhinitis frequently coexists with asthma [3], and it is often a long-standing condition that goes undetected in the primary-care setting. Over the last few years, two new antihistamines and a novel combination intranasal/antihistamine spray have been added to our treatment armamentarium for allergic rhinitis. $\mathrm{AD}$ is one of the most common skin disorders in children [4], and is often the initial step in the "atopic march" (the sequential development of allergic disease manifestations during early childhood), which leads to asthma and/or allergic rhinitis in the majority of afflicted patients [5]. Recently, a new biologic has been added to the treatment options for this condition. Often referred to as "asthma of the esophagus", EoE is an atopic inflammatory disease of the esophagus that has also become increasingly recognized in children and adults over the last $15-20$ years. This supplement provides an overview of the epidemiology and pathophysiology of these common allergic conditions as well as practical strategies for their diagnosis and management.

Allergen-specific immunotherapy is the only potentially disease-modifying therapy for allergic disease and has been proven to be effective for the treatment of allergic rhinitis/conjunctivitis, allergic asthma and stinging insect hypersensitivity. However, despite its proven efficacy, it is frequently underutilized in Canada. In this supplement, the authors review the indications and contraindications, patient selection criteria, and the administration, safety and efficacy of allergenspecific immunotherapy. Importantly, we now have new sublingual immunotherapy products available for the treatment of allergic rhinitis which offer multiple potential benefits over the subcutaneous route, including the comfort of avoiding injections, the convenience of home administration, and a favourable safety profile. It is 
important to note that we are also on the brink of using food immunotherapy in the treatment of food allergy.

Anaphylaxis is an acute, potentially fatal systemic allergic reaction that requires prompt recognition and treatment; however, both patients and healthcare professionals often fail to recognize and diagnose its early signs and symptoms. The accurate diagnosis and appropriate management of food allergy is also critical since accidental exposure to even minute quantities of the "culprit" food may result in anaphylaxis. The authors discuss the causes, clinical features, diagnosis and management of anaphylaxis and food allergy. In this supplement update, we have divided the topic of food allergy into immunoglobulin E (IgE)-mediated and non-IgE-mediated disease. Importantly, we have had a dramatic change in our approach to early food introduction and, therefore, have added an article on this topic in this update. We now encourage the early introduction of potentially allergenic foods in infancy.

In this supplement, we also review the pathophysiology, diagnosis and treatment of urticaria as well as the work-up and management of isolated angioedema, which varies considerably from that of angioedema that occurs in the presence of urticaria. Although isolated angioedema is often self-limited, laryngeal involvement can lead to fatal asphyxiation in some cases; therefore, prompt recognition and management are imperative. Over the last few years, new treatments for urticaria and angioedema have become available that have expanded our therapeutic options and improved the lives of our patients suffering from these conditions.

Drug allergy encompasses a spectrum of immunologically-mediated hypersensitivity reactions that not only affect patient quality of life, but that may also lead to delayed treatment, unnecessary investigations, and even mortality. In this supplement, the authors examine the most common drug-induced allergic reactions, such allergies to penicillin, sulfonamides, cephalosporins, radiocontrast media, local anesthetics, general anesthetics, acetylsalicylic acid (ASA), non-steroidal anti-inflammatory drugs (NSAIDs) and monoclonal antibodies. The authors also discuss multiple drug hypersensitivity (MDH), a rather novel syndrome characterized by delayed hypersensitivity reactions to two or more structurally unrelated drugs.

This supplement also provides an overview of the major categories of PIDs (a heterogeneous group disorders that result from defects in immune system development and/or function). Although the clinical manifestations of PIDs are highly variable, most disorders involve an increased susceptibility to infection. In fact, many PIDs present as "routine" respiratory infections and, therefore, may go undetected in the primary-care setting. The authors also discuss how the current view of PIDs includes an increasing number of syndromes that are associated with autoimmunity and immune dysregulation as predominant features, rather than an overt pathological risk of infections. This concept of immune dysregulation as "immunodeficiency" is novel and will become increasingly important in the field in the coming years.

For each of the above-mentioned articles, key takehome messages are summarized for quick reference and, where applicable, easy-to-follow flow charts, tables and algorithms are provided to assist clinicians in the identification, diagnosis and treatment of these common allergic diseases. We are confident that readers will not only find this updated supplement educational and informative, but that it will also provide clinicians with a solid base of knowledge and skills in allergy and immunology which they can then incorporate into their respective clinical practices to help improve the care and management of patients with allergic disease. It is also our hope that this supplement will spark further interest in these conditions and in our specialty.

Finally, we would like to thank all of the authors who set aside time from their numerous commitments to write and review these informative articles, the peer reviewers for providing their highly-valued feedback, and the Canadian Society of Asthma and Clinical Immunology (CSACI) and other sponsors who provided the support needed for the development of this important educational initiative.

We sincerely hope you enjoy this updated supplement! Harold Kim, MD, FRCPC

Richard Warrington, MB, BS, PhD, FRCPC

Wade Watson, MD, MEd, FRCPC

\section{Abbreviations}

AD: atopic dermatitis; EoE: eosinophilic esophagitis; PIDs: primary immunodeficiency disorders; IgE: immunoglobulin E; ASA: acetylsalicylic acid; NSAIDs: non-steroidal anti-inflammatory drugs; $\mathrm{MDH}$ : multiple drug hypersensitivity; CSACl: Canadian Society of Asthma and Clinical Immunology.

\section{Declarations}

Authors' contributions All authors wrote and/or edited sections of the manuscript. All authors read and approved the final manuscript.

\section{Author details}

${ }^{1}$ McMaster University, Hamilton, ON, Canada. ${ }^{2}$ Western University, London, ON, Canada. ${ }^{3}$ University of Manitoba, Winnipeg, MB, Canada. ${ }^{4}$ Division of Allergy, Department of Pediatrics, IWK Health Centre, Dalhousie University, Halifax, NS, Canada.

\section{Acknowledgements}

This article is an update to the Introduction From the Editors that originally appeared in the supplement entitled, Practical Guide to Allergy and Immunology in Canada, which was published in Allergy, Asthma \& Clinical Immunology in 2011 (available at: https://aacijournal.biomedcentral.com/articles/supplement s/volume-7-supplement-1). 
The authors would like to thank Julie Tasso for her editorial services and assistance in the preparation of this manuscript.

\section{Competing interests}

Dr. Harold Kim is Vice President of the Canadian Society of Allergy and Clinical Immunology, Past President of the Canadian Network for Respiratory Care, and Associate Editor of Allergy, Asthma and Clinical Immunology. He has received consulting fees and honoraria for continuing medical education from AstraZeneca, Aralez, Boehringer Ingelheim, CSL Behring, Kaleo, Merck, Novartis, Mylan, Pediapharm, Sanofi, Shire and Teva. Dr. Richard Warrington is the past president of the Canadian Society of Allergy and Clinical Immunology and Editor-in-Chief of Allergy, Asthma and Clinical Immunology. He has received consulting fees and honoraria from Nycomed, CSL Behring, Talecris, Grifols, Novartis and Shire. Dr. Wade Watson is an Associate Editor of Allergy, Asthma and Clinical Immunology and has received honoraria for continuing education from Pfizer Canada.

\section{Availability of data and materials}

Data sharing not applicable to this article as no datasets were generated or analyzed during the development of this review.

\section{Consent for publication}

Not applicable.

\section{Ethics approval and consent to participate}

Ethics approval and consent to participate are not applicable to this review article.

\section{Funding}

Publication of this supplement has been supported by AstraZeneca, Boehringer Ingelheim, CSL Behring Canada Inc., MEDA Pharmaceuticals Ltd. Merck Canada Inc., Pfizer Canada Inc., Shire Pharma Canada ULC, Stallergenes Greer Canada, Takeda Canada, Teva Canada Innovation, Aralez Tribute and Pediapharm.

\section{About this supplement}

This article has been published as part of Allergy, Asthma \& Clinical Immunology Volume 14 Supplement 2, 2018: Practical guide for allergy and immunology in Canada 2018. The full contents of the supplement are available online at https ://aacijournal.biomedcentral.com/articles/supplements/volume-14-suppl ement-2.

\section{Publisher's Note}

Springer Nature remains neutral with regard to jurisdictional claims in published maps and institutional affiliations.

Published online: 12 September 2018

\section{References}

1. Public Health Agency of Canada. Life and breath: respiratory disease in Canada. Ottawa: Public Health Agency of Canada; 2007. http://www. phac-aspc.gc.ca/publicat/2007/lbrdc-vsmrc/index-eng.php. Accessed 15 July 2010.

2. FitzGerald JM, Boulet LP, Mclvor RA, Zimmerman S, Chapman KR. Asthma control in Canada remains suboptimal: the Reality of Asthma Control (TRAC) study. Can Respir J. 2006:13(5):253-9.

3. Bourdin A, Gras D, Vachier I, Chanez P. Upper airway 1: allergic rhinitis and asthma: united disease through epithelial cells. Thorax. 2009;64(11):999-1004.

4. Krakowski AC, Eichenfield LF, Dohil MA. Management of atopic dermatitis in the pediatric population. Pediatrics. 2008;122:812-24.

5. Spergel JM, Paller AS. Atopic dermatitis and the atopic march. J Allergy Clin Immunol. 2003;112:S128-39.
Ready to submit your research? Choose BMC and benefit from:

- fast, convenient online submission

- thorough peer review by experienced researchers in your field

- rapid publication on acceptance

- support for research data, including large and complex data types

- gold Open Access which fosters wider collaboration and increased citations

- maximum visibility for your research: over $100 \mathrm{M}$ website views per year

At BMC, research is always in progress.

Learn more biomedcentral.com/submissions 